\title{
A-Review on Nanorods-An Overview from Synthesis to Emerging, Device Applications and Toxicity (A-Review)
}

\section{LAITH K. OBEAS ${ }^{1 *}$, ALWALEED KHALID GHALIB ${ }^{2}$, G. ABDUL KAREEM-ALSULTAN ${ }^{3 *}$, N. ASIKIN-MIJAN ${ }^{4}$ and ROBIAH YUNUS ${ }^{3}$}

\author{
${ }^{1}$ Technical Institute of Babylon, Al-Furat Al-Awsat Technical University (ATU), Iraq. \\ ${ }^{2}$ Thi-qar oil company, Iraq. \\ ${ }^{3}$ Chemical and Environmental Engineering Department, Faculty of Engineering, \\ Universiti Putra Malaysia, 43400 UPM Serdang, Selangor, Malaysia. \\ ${ }^{4}$ Department of Chemical Sciences, Faculty of Science and Technology, Universiti \\ Kebangsaan Malaysia, 43600 UKM Bangi, Selangor Darul Ehsan, Malaysia. \\ *Corresponding author E-mail: laith1978@ atu.edu.iq, kreem.alsultan@yahoo.com
}

http://dx.doi.org/10.13005/ojc/370201

(Received: January 09, 2021; Accepted: March 31, 2021)

\section{ABSTRACT}

\begin{abstract}
Nanorod technology has gone a long way in the field of science and to a great extent, it has been a dictator of the past, present, and future of technology work. This article shows a detailed explanation of the course of nanorod production and the application from start to finish. Various kinds of nanorods have been found to exist and they have been maximally put to good use in different fields of life. These nanorods, however, did not just come into existence, some of them were formed from some nanorod compounds while some other ones came into being as a result of the combination of two or more compounds. These particles in their raw form can be generally useful, but its specific functions cannot be gotten without proper optimization. Various researchers have, dedicated their time to proper optimization of the numerous nanorods that are available in order to find an optimum result science. This course scans through the birth, processing as well as the highly valued application of nanorods.
\end{abstract}

Keywords: Nanorod, Nanotechnology, Nanomaterials, Gold, Zinc oxide, Magnetic, Carbon.

\section{INTRODUCTION}

Nanoscience, nanotechnology, and nanomaterials are now a central field of science and technological activity. A quick definition of the terms above will give an insight into the subject matter. Nanoscience refers to the study, manipulation, and engineering of matter, particles, and structures on the nanometer scale. Nanotechnology refers to the creation of useful materials, devices, and systems using the particles of nanometer length scale and exploitation of new properties at that length scale. It is the application of nanoscience involving the use of nanomaterials and nanosize components in useful products.

This is an Open Access article licensed under a Creative Commons license: Attribution 4.0 International (CC- BY). Published by Oriental Scientific Publishing Company @ 2018 


\section{Nanomaterials}

These are materials of unit size varying from 1 to 1000 nanometers. Classification of nanomaterials can be based on size and shape. Nanoparticles, nanocapsules, nanofibers, nanowires, fullerenes, nanotubes, nano-springs, nanobelts, quantum dots, and nanofluids have been classified as nanomaterials based on this classification. Nanorod is a new and fascinating topic in the field of nanoscience and nanotechnology which has been experiencing constant groundbreaking changes in recent years. Recently, due to the unusual physical properties, it has drawn much special research attention. The nanorods are nanoscale material structures. Each dimension to the nanorod ranges from 1 to $100 \mathrm{~nm}$. This can be synthesized from metals or materials with semiconductor. These are provided by direct synthesis of chemicals. A mixture of ligands serves as shape regulation agents and binds with various strengths to specific aspects of the nanorod. This allows space to expand at different levels for the various facets of the nanorod, creating an elongated object. They are called solid nanofiber.

Because of their high surface area to volume ratio, nanoscale materials such as fullerenes, quantum dots, and metallic nanoparticles have special properties. Nanorods show fluorescence enhanced over bulk metals and nanospheres. Numerous nanomaterial characteristics depend on size and shape including its catalytic, magnetic, electrical, chemical and physical properties. Nanostructure processing approaches are numerous. Nanostructures include nanorods, nanoparticles, quantum dots, nanocrystals, nanowires, nanowhiskers, hybrid nanostructures, etc. Many other words used in nanotechnology will be briefly described here, as the words used in this review article will be used.

\section{Nanoparticle}

A solid particle in the range between 1 and $100 \mathrm{~nm}$ which may be non-crystalline, a crystallite mixture or a single crystallite. This can be arranged into surface layers, offering a broad surface area and, therefore, enhanced operation applicable to a variety of possible applications such as catalysts. Quantumdot: This is a nanostructure of semiconductors in which the particles are bound in all three directions and cannot travel freely in any direction of space. It is a device of zero-dimensional existence. Nanocrystal: A solid substance in the nanometer range and is a single crystal. Nanowire: a nanostructure on the order of a nanometer by diameter. Fullerenes: Carbon 60 Increasingly, the use of nanorods and nanostructures and their applications in various electronic devices, biosensors, solar cells and nanodevices. To research and exploit the attractive properties of nanorods, a magnificent extinction coefficient is needed which can predict the concentration of a solution at a particular absorption.

\section{Types of nanorods}

There are different types of nanorods in existence. These include:

\section{- $\quad$ Silver nitrate nanorods \\ - Carbon nanorods \\ - Manganese oxide nanorods \\ - Tin oxide nanorods \\ - Zinc oxide nanorods \\ - Gold nanorods \\ - $\quad$ Tungsten trioxide nanorods \\ - Magnetic nanorods}

\begin{abstract}
A few things will be discussed about some selected nanorods.
\end{abstract}

\section{Silver nitrate nanorod}

Silver nanowires embedded in a polymer can be employed to make conductive layers that can flex, without damaging the conductor.

\section{Manganese oxide nanorod}

This nanorod is used to sense potassium ion concentration in food and water. For the fabrication of a non-enzymatic potassium ion sensor, $\mathrm{MnO}_{2}$ nanorods were synthesized using a low-temperature sol-gel process.

The electrochemical characteristics of the fabricated non-enzymatic potassium sensor reveal good sensing performance in terms of
- $\quad$ Sensitivity
- Selectivity
- $\quad$ Long-term stability
- Reproducibility 


\section{Tungsten trioxide nanorods}

These nanorods are produced by a hydrothermal method which involves the growing of nanostructures on polyester fabric because of its ability to withstand temperature.

Tungsten trioxide has become popular in recent years in vast and diverse fields due to the following enhanced functional properties:

- $\quad$ Electrochromic property: This means that it has the ability to go through optical coloration when a voltage is applied to it. It is a phenomenon shown by some materials when there is a persistent and reversible change in their color when electricity is made to pass through them.

- $\quad$ Photocatalytic property

- $\quad$ Electrostatic property

- $\quad$ Photoluminescent property

- Gas-sensing property

- Ultraviolet resistance property

It is synthesized by dissolving a particular amount of sodium tungstate in freshly prepared distilled water while stirring mechanically until all is dissolved. In the meantime, hdrochloric acid is gradually added to the solution prepared above. This causes the color change from crystal white to yellow and becomes viscous. The above solution is then filtered to remove the excess amount of hdrochloric acid and the precipitates are oven-dried.

The above process describes the synthesis of tungsten trioxide nanorods.

These nanorods are used majorly in the textile industry. Other applications include.

- $\quad$ Gas and humidity sensing

- Optical devices

- $\quad$ Electrochromic windows

- Catalysts

- Tumor CT Imaging

- $\quad$ Photothermal therapy

\section{Tin oxide nanorod}

This tin oxide nanorod can be produced by non-hydrothermal synthesis at moderate temperatures. It can also be synthesized by the following methods:
- $\quad$ Flame synthesis

- $\quad$ Facile synthesis of single-crystal

It has found application in Li-ion batteries as a lithium storage compound.

Other applications include:

- Semiconductor gas sensor

- Optoelectronics

- Engineering of one-dimensional nanomaterials

- Nanoscale soldering applications

\section{Carbon nanorods}

Since of their attractive physical and chemical properties, carbon has drawn considerable attention over the last few decades. To date, such nanoparticles as carbon ${ }^{1}$, nanotubes ${ }^{2}$, ions ${ }^{3,4}$, nanowires ${ }^{5}$, nanofibers ${ }^{6}$ and carbon nanorods ${ }^{7,8}$ have been recorded. Such carbon nanometer materials are supposed to have a fairly large bandgap and to behave like a semiconductor. More interestingly, carbon nanorods were primarily used in batteries as fillers ${ }^{9}$ and high-performance electrode materials ${ }^{10}$ To date, numerous methods for their syntheses have been suggested, such as ball milling ${ }^{11,12}$ chemical vapor deposition ${ }^{11}$, laser ablation, chemical reduction and co-precipitation ${ }^{13,14}$. More recently, new synthetic methods have been developed, such as flame synthesis, sol-gel, microwave plasma and low energy cluster beam deposition ${ }^{9,15,16}$.

Carbon nanomaterials have drawn interest over the years due to their physical and chemical materials. Carbon nanorods are elongated particles ranging from 10 to 120 nanometers $(\mathrm{nm})$ with a specific surface area in the $30-70 \mathrm{~m}^{2} / \mathrm{g}$ range. The carbon nanomaterials are nanoparticles, nanowires, carbon nanorod, nanotubes, nanohorns, nanowhiskers etc. These materials have a relatively large bandgap and expected to act as semiconductors. Recent studies have proposed different methods for the synthesis ${ }^{1}$. The methods include:

- Chemical vapor deposition

- Coprecipitation

- $\quad$ Ball Milling

- Laser ablation

- Chemical reduction 
More recent methods include:

$\begin{array}{ll}\text { - } & \text { Flame synthesis } \\ \text { - } & \text { Sol-gel } \\ \text { - } & \text { Microwave plasma } \\ & \text { Low energy cluster beam deposition }\end{array}$

\section{ZnO nanorods}

Nanorod zinc oxide $(\mathrm{ZnO})$ is also known as nanowire. This has emerged as one of the most popular electronic device materials such as solar cells, light-emitting devices, transistors, and sensors. The diverse structures generate special, useful, and original characteristics suitable for high-performance system development. According to the following structures the $\mathrm{ZnO}$ nanorod array has various applications ${ }^{2}$ :

\section{- $\quad$ Porosity \\ - $\quad$ Large surface area \\ - $\quad$ High electron mobility}

It is a unique functional semiconductor material which has a direct bandgap energy of 3.37 $\mathrm{eV}$, has a high excitation binding energy of $60 \mathrm{meV}$ at room temperature and an effective ultraviolet luminescence. Different $\mathrm{ZnO}$ nanorod types have been grown and the effects of growth conditions have been studied by several groups.

Photodetection and photoresponse of Zinc oxide nanorods depend on the surface condition, quality of structure, methods of production and rate of oxygen adsorption and photodesorption. The use of appropriate dopant, improvement of the structure, surface passivation and putting other things in place can enhance the photoresponse and photosensitivity.

It has been intensely used to fabricate nanoscale electronic devices.

\section{The growth of Zinc oxide nanorods}

Zinc oxide is a compound semiconductor group II-VI whose ionic character is between the covalent and ionic semiconductors. For all of Zinc oide's crystal structures, such as wurtzite, zinc blende, and rock salt, only the phase of wurtzite is thermodynamically stable. Thermal vapor deposition, metal-organic chemical vapor deposition, molecular beam epitaxy, and top-down approach by etching may cultivate zinc oxide nanorods with changed shape and order. Of all these approaches, vapor deposition and chemical methods are the techniques commonly used for the popularity of their controllability, repeatability, efficiency and mass production $^{3}$.

\section{Gold nanorods}

Gold nanorods are cylindrical rods with a width of less than 10 to more than 40 nanometers and a length of up to several hundred nanometres. We are seen as excellent candidates for uses of biological sensing because the absorbance band varies with the refractive index of the local material which allows for extremely precise sensing. We display the different color depending on the size and aspect ratio which gives the possibility to use it in specific optical applications. The gold nanorod synthesis that works can be divided into three main stages:

- Gold Nanorod Fabrication

- $\quad$ Silica Shell Formation

- DNA Functionalization

\section{Preparation of gold nanorods}

There are three methods used in wet chemistry to produce this type of nanorod. Each new method comes with an improvement in material quality and also accompanied by a decrease in difficulty of the preparation of the nanorod. The methods are listed below:

(i). Template method: This process is based on gold electrochemical deposition in the alumina template membrane or inside polycarbonate pores of nanoporous substances. This was initially developed by Martin and his colleagues 20 . The method can be represented as this: A small amount of silver or copper is quickly scattered onto the alumina template membrane to act as an electrodeposition conductive sheet. This serves as the base upon which to electrochemically develop gold nanoparticles. Gold is subsequently electrodeposited within the alumina nanopores. A partial dissolution of both the membrane template and the copper or silver film layer occurs in the presence of a polymeric stabilizer such as polyvinylpyrrolidone. The final stage is the stage where the rods are dispersed by special 
means such as sonication or agitation, in either water or organic solvents. The length and diameter of the generated nanorods can be determined by the amount of gold deposited and the template membrane's pore diameter, respectively. Nevertheless, the basic and foundational drawback of this approach is yield. Since only monolayers of nanorods are prepared, even small amounts of stalks are difficult to prepare.

(ii). Electrochemical method: This method which provides a synthetic way for preparing high yields of gold nanorods, was first described by Wang and co-workers ${ }^{4}$. The nanorod production is conducted with a non-complex two-electrode type electrochemical cell. For a successful process, certain conditions must be provided:

- A gold metal plate as a sacrificial anode.

- A platinum plate similar to a cathode.

- A typical current of 3 milliamperes and a typical electrolysis time of 30 minutes.

- Electrolytic solutions to immerse both electrodes. The solutions serve different functions. For example, hexadecyltrimethylammonium bromide acts as a stabilizer for the nanoparticles to prevent clumping; tetradodecylammonium bromide plays the role of rod-inducing cosurfactant and other solutions such as cyclohexane and acetone are also contained in the solutions.

The concentration of silver ions and their release rate are the determinants of the nanorod length.

(iii). Seeded growth method.

(iv). Other methods include the photochemical method.

\section{Magnetic nanorods}

For the last two decades, magnetic nanorods have been at the forefront. Centuriesold magnetic technologies have been used in engineering, biomedical etc. The magnetic nanorod classification is based on the magnetic strength. Such nanorods are strong and are made from iron, cobalt, and stable spinel ferrite materials. Since of the weak driving fields ${ }^{21}$ the materials are adopted. Magnetic characteristics include chemical stability, biocompatibility and superparamagnetic characteristics.

One of the most important of the magnetic nanorod is its use in the biomedical field.

\section{Production of magnetic nanorods}

Various physical and chemical methods are adopted in the synthesis of magnetic nanorods. 5,6

Chemical method: These methods include:

(i). Thermal decomposition,

(ii). Hydrolysis,

(iii). Wet chemical, hydrothermal,

(iv). Sol-gel,

(v). Template-mediated

(vi). Co-precipitation.

Physical method: With this method, there are no reactions just physical processes. These methods are:

(i). Adsorption,

(ii). Electrospinning,

(iii). Plasmon-enhanced spectroscopy,

(iv). Ultraviolet fluorescence,

(v). Adhesion,

(vi). Novel flame-gradient,

(vii). Electron beam,

(viii). Direct growth on Titanium foil and

(ix). Layer by layer.

\section{Physicochemical method}

This method controls the formation of the core, growth and other processes associated with the particle size. It is also the photoelectrochemical method.

In recent years, magnetic nanorods have found further applications in the market, high-density magnetic storage systems, images, catalysts, refrigeration devices, medical diagnostics, And electronic components such as photocatalysts, gas sensors and lithium-ion battery electrodes. Nanorod diagnostic applications in medicine are based on their chemical and physical properties, which include: 
1. Uniformity

2. Chemical composition

3. Size

4. Magnetic properties

5. Homogeneity of a crystal structure

6. Surface characteristics

7. Biocompatibility

8. Adsorption

9. Roughness

10. Low toxicity

11. Flexibility

12. Solubility

\section{Mechanisms of nanorods material production}

The mechanisms for nanorod material production depend on the nanomaterial to be produced. However, the general idea is the same as the seed-mediated method. The seed-mediated procedure has been employed to make surfactantcoated nanorods. This method produces stabilized nanorods ${ }^{7}$.

It has been proven that both temperature and reaction time are necessary factors in determining the morphology and aspect ratios of nanorods.

The mechanisms of selected nanorod material will be explained in details here.

\section{Zinc oxide nanorod}

Myriads of methods have been used to produce seeds. Fabrication and characterization of zinc oxide nanorods using hydrothermal method reveal the effects of certain parameters such as:

- Heat-treatment temperature

- $\quad$ Zinc nitrate concentration

- $\quad \mathrm{pH}$ of hydrothermal bath solution

- hydrothermal reaction time

\section{Gold nanorod}

Synthesis of gold nanorods has been carefully studied using three known methods over time. All of these syntheses require both thermodynamic and kinetic control. For this reason, careful specifications should be taken into consideration while synthesizing. Take for instance, for the synthesis of gold particles, the average diameter is just sufficient to describe the colloid compound. For a gold nanorod, however, apart from the diameter, the length, thickness, aspect ratio, reduction yield as well as the shape yield are matters that should be taken into proper consideration. This means the synthesis process has to be carefully monitored from the start to the finish ${ }^{8,9}$.

The seeded protocol method is the first to be considered as it came as a turning point in the development of efficient nanorod wet synthesis. The seeds (small golden nuclei upon which other complex structures are built) are first separately prepared by nucleation, after which the seeds are added to the growth solutions for nanorod production. It should be worthy of note that there is usually a need to add a strong reducing agent, usually, sodium borohydride which leads to in situ formations of the seed through partial reduction of the gold salt precursor. The kind of nanorod to be built is worthy of note here as most of them have the different specifications in relations to the factors stated above ${ }^{10}$.

The electrochemical method as well as the template methods have also been employed in the synthesis of gold nanorods, though from what it looks like, the seeded protocol method is still the most widely used but not the best when relatively compared.

\section{Magnetic Nanorods}

Of the numerous synthesis methods of this ever appreciating and swiftly expanding nanorod, the colloidal synthesis is still the one leading the pack as many journals have gone down and research works done by employing this form of synthesis.

The colloidal synthesis method spreads its mechanism of ligand control. It also makes it possible for the aspect ratio of the magnetic nanorod to be controllable just by changing the reaction temperature. This is a facile way of synthesizing magnetic nanorods which is more effective and highly economical. Some researchers have implemented the strategy involving the reaction of iron (III) acetylacetonate with polyethyleneimine in the presence of oleylamine and phenyl ether. The resulting compound is then thermally decomposed. This makes the length and diameter as well as the aspect ratio of the synthesized nanorods controllable. 


\section{Carbon nanorods}

The synthesis of carbon nanorods has been found out to be best by reduction of carbon bisulfide $^{11,12}$. Researchers have explored this method of synthesis by creating a hexagonal graphite which is capable of causing the refraction of $\mathrm{X}$-ray particles when the light is being focused on it. It is a more economical and highly used method of carbon nanorod synthesis ${ }^{13,14}$.

This method involves the reduction of carbon bisulfite in 600-degree Celcius. This yields a high percentage of carbon nanorod evident under the scanning electron microscope as well as the Transmission electron microscope where novel Y-junction carbon nanorods are detected, capable of causing an $\mathrm{X}$-ray refraction which is an hexagonal graphite $^{15,16}$.

\section{Optimization of nanorods material production}

As it is well known that most materials in their raw form are close to being useless, such as the need to optimize them for good use is a very expedient. This same principle applies to nanorods, this new technology that is getting the attention of all and sundry today can only be effectively used provided it is well optimized and kept within its range. Various works have been done by devoted scientists to this field in the past and some other works relating to the field of nanotechnology are still being done. As stated above, the various types of nanorods that have been discovered so far have various uses which will all be spelled out in details very soon, nonetheless, the need to optimize them in order to get them to good use and to make sure they are working fine and well cannot be overemphasized ${ }^{17,18}$.

Getting the right material and the specific product to use in the diagnosis and treatment of a particular defective condition is the most basic and one with the highest importance when it comes to putting nanorods into good use. The different types of nanorods that we have, carbon, gold, zinc oxide, magnetic and lots more all have their general and specific uses. It is important to note that each specific use of a particular type of nanorod is peculiar to it and cannot be perfectly replaced by another, the gold nanorod is explicitly used in a particular niche. This is grossly due to its shape and the particular kind of material is made with. Imagine using another nanorod in its stead, it will only aggravate what was initially intended to be resolved ${ }^{19}$.
The size of a rod is just as important as the experiment in which the nanorod is going to be performed. For some experiments, the thicker the material, the less effective the result will yield while the case is reversed for some other experiments. For instance, in a research performed by the acoustical society of America, in a bid to use gold nanorods in the minimization of cell toxicity and in the creation of a maximum photoacoustic response, it was observed that smaller sized gold nanorods will be more effective to getting the desired result. Some other experiments that have been carried out by other scientists have seen the positive effect of size in the optimal use of nanorods ${ }^{20}$.

One other factor that is worthy of note when trying to optimize nanorods is the adsorbing capability. This is particularly important for Nanorods that relates to fluorescence-related experiments. Zinc oxide nanorod is a big one in this niche as many tests have been carried out in the lab and lots of journals have been written in a bid to determine how applicable this Nano compound is to some fields of life. Its optimization has been observed to be dependent on its adsorbing capability. The adsorbing capability of the material in use is dependent on the $\mathrm{pH}$, sonication time, adsorbent mass as well as other factors which should be considered ${ }^{21}$.

One other optimization capacity worthy of note is the aspect ratio of a particular nanorod. Gold nanorods are especially important in working with this type of property as it goes a long way in determining how well the material can be used and how well it responds to the effect it is intended to be used ${ }^{22}$.

Many times, nanorods are always combined to form compounds that are capable of producing more lasting and highly effective responses. Metallic nanorods, for instance, have been said to have been worked with, combining it with copper compounds. Also, zinc oxide nanorod has also been combined with other particles and compounds in a bid to get it optimized and produce a more desirable response. So, the combining capacity of a particle nanorod will go a long way in determining its effectiveness at work ${ }^{23}$.

Many optimizations have been done since the time nanorods have come into existence and many works have been done by lots of scientists. Nanorods are useful in virtually every niche of life. 
The field of medicine in relations to genetics, cellular function as well as some disease conditions have been identified to be useful areas of exploration. Nanorod technology has by far eaten deeply into these areas and it has been used for a whole lot of research works as well as the treatment of some tumors and genetically linked disease conditions. From in vivo therapeutic and imaging efficiency, to minimum cell toxicity and maximum photoacoustic response, down to rapid diagnostic testing, medical scholars are improving and widening their scope every passing day, leveraging on the functions of nanorod particles in performing these tasks ${ }^{24,25}$.

The world of technology, as well as engineering, is one of the largest in which nanorod technology has really been explored. Solar cells have been sensitized, biomolecular emissions have been enhanced, and lots of other bioengineering applications have been explored and brought into reality with nanorod technology ${ }^{26,27}$. The need for consistent optimization cannot be overemphasized as this goes a long way in determining how well a particular nanorods particle is going to function and the results it will yield ${ }^{28,29}$.

\section{Industrial application}

Nanorods have wide application across all fields. One potential application of nanorods is in display technologies because the reflectivity of the rods can be changed by changing their orientation with an applied electric field. Generally speaking, nanotechnologies can enhance energy efficiency across every branch of the industry. It is also applied in microelectromechanical systems (MEMS). It also functions as therapeutic and diagnostic agents which have made it useful in cancer therapy. Generally, nanorods can be used in the following fields ${ }^{[11,30}$.

\section{In Medicine}

The small size of nanoparticles helps them to readily interact with biomolecules on the cells and they are able to gain access to many areas of the body to detect disease and deliver treatment. Nanorods can be used in computerized tomography imaging of tumors. Nanoshells have successfully recognized cancer cells and killed the tumor cells without damaging normal neighboring cells. Nanoparticles are used for molecular imaging of malignant lesions. Nanowires are used as a medical sensor. They can detect the presence of mutated genes associated with cancer and help in managing the diseased patient. Nanomaterials increase the lifespan of implant materials. Examples include nanocrystalline zirconium oxide, nanocrystalline silicon carbide etc. they could also present an attractive alternative material for implants ${ }^{31,32}$.

\section{In Military wears}

Enhanced nanomaterials form the basis for the creation of the advanced battle suit. The technologies include energy-absorbing materials that can withstand blast waves, and sensors that can detect or respond to chemical and biological weapons.

\section{In water purification}

it is used significantly in the desalination process.

\section{In batteries}

Since there is a great demand for portable electronic equipment and devices, there is a need for lightweight and high-energy density batteries. Nanorods come into play. The industrial application of individual nanorod will be discussed further: ZnO nanorod: Zinc oxide nanorod also known as nanowire has been applied in various fields of life. Its properties have attracted the interest of researchers and companies to use this material. A few of the endless applications will be enumerated here:

\section{In electronics}

$\mathrm{ZnO}$ nanorods were used to build electrodes that would require flexible and thinner flat panel displays than current flat panel displays. It was used for building transistors without $\mathrm{p}-\mathrm{n}$ junctions. For making dense memory devices an alloy of nickel and iron nanowires can be used. It was also used to build sensors which can detect a range of chemical vapors ${ }^{12}$.

\section{In energy}

It has been used to produce low cost flexible solar cells with high efficiency. The solar cells are developed using graphene coated with Zinc oxide nanowires. It has been demonstrated by some researchers that sunlight can be concentrated in nanowires.

\section{In the environment}

It has been used to produce nanowire mats that can absorb oil spills. 


\section{Carbon nanorod}

Some decades ago have witnessed a breakthrough in the use of carbon nanorods. Its usage includes:

- Device modeling,

- Energy storage,

- Boat hulls,

- Automotive parts,

- Water filters,

- Sporting goods,

- Coatings,

- $\quad$ Actuators and

- Thin-film electronics,

- Electromagnetic shields

\section{Magnetic nanorod}

Aided magnetic field self-assembly of iron nanoparticles containing magnetic dipole moment resulted in the creation of magnetic and mechanically rigid nanoscale rods. Synthesis products have been used in many fields, several of which are described below:

- Development of magnets with unusual magnetic properties because of their extremely broad interface with grains.

- Magnetic nanorods are used in motors, scientific instruments such as magnetic resonance imaging ( $\mathrm{MRI}$ ) used in hospitals, and microsensors.Magnetic materials have applications in data storage. The capacity of computer hard disks storage capacity can be increased with magnetic nanomaterials.

- $\quad$ Photograph

- High-density magnetic storage devices,

- $\quad$ Cooling devices

- Catalysts

- $\quad$ Electronic components such as photocatalyst

- Medical diagnostics

- $\quad$ Electrodes in lithium-ion batteries

- Gas sensors

\section{Magnesium oxide nanorods}

It is used in sensing potassium ion in water samples.

\section{Tungsten trioxide nanorods}

They are applied in the textile industry. Others include:
- $\quad$ Gas and humidity sensing

- Optical devices

- $\quad$ Electrochromatic windows

- Catalysts

- $\quad$ Tumor CT Imaging

- Photothermal therapy

Tin oxide

It is used as a lithium storage compound in Li-ion batteries.

Other applications include its use:

- Semiconductor gas sensor

- Optoelectronics

- Engineering of one-dimensional nanomaterials

- $\quad$ Nanoscale soldering applications

Synthesis of MNPs for demulsification applications Co-precipitation synthesis

Co-precipitation is the most widely applied process for the synthesis of MNPs; In a number of disciplines, these have been used for demulsification, with the main emphasis on the separation of oil and water in the petroleum and petrochemical industries. Co-precipitation of an aqueous salt solution requires the synthetic path to MNPs, accompanied by the introduction of the foundation under an inert environment at elevated temperatures ${ }^{33}$, have thoroughly explored the geometric flow map explaining the synthetic route of MNPs by co-precipitation ${ }^{33}$. Two major strategies are typically involved in the synthesis of spherical MNPs by co-precipitation: (1) by oxidising $\mathrm{Fe}(\mathrm{OH})_{2}$ with various oxidising agents and accompanied by (2) ageing in aqueous media of the mixtures of $\mathrm{Fe}(\mathrm{OH})_{2}$ and $\mathrm{Fe}_{3} \mathrm{O}_{4}$ to convert the morphologies initially developed into spherical MNPs of almost equal duration. The size of the resulting iron oxide, however, is calculated by the form of salt used, the ionic power, the reaction mixture temperature, the $\mathrm{pH}$ and other determining parameters, such as the pace at which the simple solution is applied and the rate of stirring. $\mathrm{A} \mathrm{pH}$ in the range of 8-14 should be maintained by the standard MNP provided by this process, and the particle sizes can be regulated by changing the ionic intensity and $\mathrm{pH}$ of the medium while holding the $\mathrm{Fe}^{3+} / \mathrm{Fe}^{2+}$ ratio at 2/1. Indeed, this synthetic path has been used to manufacture MNPs to demulsify all types of emulsions ${ }^{34,35}$. 


\section{Solvothermal synthesis}

Among the prominent methods mentioned in the literature for the development of MNPss is the Solvothermal technique, also called hydrothermal synthesis ${ }^{35,36}$. This technique is one of the great and effective ways in which many materials produce crystal growth. In a closed container packed with aqueous fluid working at temperatures in the range of $130^{\circ} \mathrm{C}-250^{\circ} \mathrm{C}$ and under strong vapour pressure within 0.3-4 $\mathrm{MPa}$, the process reflects numerous chemical techniques for crystallising compounds. To create free single crystal particles, Solvothermal methods have been successfully implemented, and particles or grains produced from this process could possess superior crystallinity than those from other synthetic routes. As such, with a high crystalline domain, solvothermal synthesis is able to produce iron nanoparticles. In particular, for the treatment and separation of the emulsified oil-water mixture, MNPs obtained from this process have been well utilised. $\mathrm{Fe}_{3} \mathrm{O}_{4}$ MNPs is synthesised via the solvothermal pathway ${ }^{7}$ to split up the emulsified oil-water mixture and to differentiate water and oil into phases. Dissolving $1.62 \mathrm{~g}$ of $\mathrm{FeCl}_{3} \cdot 6 \mathrm{H}_{2} \mathrm{O}, 0.48$ $\mathrm{g}$ of trisodium citrate dihydrate, and $4.32 \mathrm{~g}$ of $\mathrm{NaAc}$ in $60 \mathrm{~mL}$ of ethylene glycol and subjecting the mixture to vigorous agitation at room temperature is a synthetic technique for the formation of $\mathrm{Fe}_{3} \mathrm{O}_{4}$ MNPs. For the solvothermal reaction phase at $200^{\circ} \mathrm{C}$ and for $12 \mathrm{~h}$, the resulting solution was transferred into a $100 \mathrm{~mL}$ closed Teflon autoclave. In the presence of $\mathrm{N}$-(aminoethyl)-amino-propyl triethoxy silane (AEAPTES), the $\mathrm{Fe}_{3} \mathrm{O}_{4}$ MNPs formed were washed with ethanol and deionized water and subjected to another reaction in order to generate $\mathrm{Fe}_{3} \mathrm{O}_{4} @$ AEAPFS MNPs. In reality, a variety of other researchers have synthesised related MNPs using $\mathrm{Fe}_{3} \mathrm{O}_{4}$ as the precursor for the demulsification of crude oil emulsions via the solvothermal method ${ }^{19}$. The solvothermal process seems to be very successful, but the main problem with this synthesis ${ }^{21,37}$ technique is the complexity of generating nanocrystals with less than $10 \mathrm{~nm}$ and excellent hydrophilic characteristics ${ }^{33}$. Particle sizes and distribution appear to rise exponentially in this system as the concentration of the precursor rises, with only residence time providing a significant effect on the mean particle size.

\section{Sol-gel synthesis}

Sol-gel synthesis is a technique mainly developed to synthesise metal oxides ${ }^{33}$. This strategy depends on the method of condensation, hydrolysis, and drying. By using metallo-organic precursors, this approach has been applied to the processing of MNPs. The active synthesis of MNPs by sol-gel techniques was recorded by ${ }^{38}$. This researcher used $0.2 \mathrm{M}$ citric acid and $0.1 \mathrm{M}$ iron nitrate for the synthesis of nanoparticles, with continuous ageing at $90^{\circ} \mathrm{C}$ for approximately $16 \mathrm{~h}$ under open atmospheric conditions. With the exception of Yashimata et al., ${ }^{39}$ who synthesised oligomeric silica/ magnetite composite through the sol-gel reaction, this approach was not used to generate MNPs aimed at destabilising stable emulsions. In their analysis, 25 percent of the ammonia solution was applied to $5 \mathrm{~mL}$ of methanol solution combined with fluoroalkyl end-capped vinyl trimethoxysilane oligomer and $100 \mathrm{mg}$ of magnetite nanoparticles. The resultant composition experienced heating for about $5 \mathrm{~h}$ at an elevated temperature. To remove impurities, the final component was precipitated under a magnetic field, and the composite product obtained was heavily washed with methanol. The benefits of sol-gel reaction to synthesis MNPs include simple particle size modulation, acquiring pure monodispersed particles and deriving nanoparticles with predetermined structures ${ }^{33,40}$.

\section{CONCLUSION}

Nanorod science and technology has gone out and about in influencing its world. The use of nanorods and nanoparticles generally has paved the way for lots of solutions as well as opened the minds of researchers into further exploration of the field. Owing to its systemic application, it is a field that can keep being studied for a very long time because of the new advances made every passing day. Nanorod synthesis, as well as its optimization, is one way of research, its application is another. These entire put together has paved the way for jobs all over the world. Science and technology graduates now have things to lay their hands upon and explore appropriately. Machines and lots of engine builders are also exploring this technique, by implementing the basic concept, they have brought into reality diverse kinds of innovations and ideas to the end that the world keeps growing and getting developed. The world of nanotechnology is that which should be greatly explored as it determines to a great extent how far and how well the scope of science and technology in this age and beyond will expand. 


\section{ACKNOWLEDGMENT}

This research did not receive any specific

grant from funding agencies in the public, commercial, or not-for-profit sectors.

\section{Conflicts of Interest}

The authors declare no conflict of interest.

\section{REFERENCES}

1. Sanchez-Garcia MD, Lagaron JM. On the use of plant cellulose nanowhiskers to enhance the barrier properties of polylactic acid. Cellulose., 2010, 17, 987-1004. https://doi. org/10.1007/s10570-010-9430-x.

2. $\quad$ Meng X.; Shi L.; Yao L.; Zhang Y.; Cui L. Calcination induced PEG-Ni-ZnO nanorod composite and its biomedical applications. Colloids Surfaces A Physicochem Eng Asp., 2020, 124658. https://doi.org/10.1016/j. colsurfa.2020.124658.

3. Bagga R. Hydrothermal growth of zinc oxide nanorods doped with manganese., 2020.

4. $\quad$ Wang X.; Liu N.; Liu Y.; Jiang L.; Zeng G.; Tan X.; Adsorption removal of $17 \beta$-estradiol from water by rice straw-derived biochar with special attention to pyrolysis temperature and background chemistry. Int J Environ Res Public Health., 2017, 14, 1-17. https://doi. org/10.3390/ijerph14101213.

5. Aisida SO.; Madubuonu N.; Alnasir MH.; Ahmad I.; Botha S.; Maaza M.; Biogenic synthesis of iron oxide nanorods using Moringa oleifera leaf extract for antibacterial applications. Appl Nanosci., 2020, 10, 305-15. https://doi. org/10.1007/s13204-019-01099-x.

6. Hilal H.; Lee S.; Jung I.; Yoo S.; Park S. Scattering Fourier Transform Biosensor: Binary Mixture Consisting of Magnetic Ni Nanorings and Plasmonic Au Nanorods. Anal Chem., 2020, 92, 10099-107. https:// doi.org/10.1021/acs.analchem.0c02065.

7. Abdulkareem Ghassan A.; Mijan N-A.; Hin Taufiq-Yap Y. Nanomaterials: An Overview of Nanorods Synthesis and Optimization. Nanorods and Nanocomposites., 2020. https://doi.org/10.5772/intechopen.84550.

8. Scarabelli L.; Sánchez-Iglesias A.; Pérez-Juste J.; Liz-Marzán LM. A "Tips and Tricks" Practical Guide to the Synthesis of Gold Nanorods. $J$ Phys Chem Lett., 2015, 6, 4270-9. https:// doi.org/10.1021/acs.jpclett.5b02123.

9. Hinman JG, Stork AJ, Varnell JA, Gewirth AA, Murphy CJ. Seed mediated growth of gold nanorods: Towards nanorod matryoshkas.
Faraday Discuss., 2016, 191, 9-33. https:// doi.org/10.1039/c6fd00145a.

10. JC N, Technology JN-, undefined. Waste Clamshell-Derived $\mathrm{CaO}$ Supported $\mathrm{Co}$ and W n.d., 2015.

11. Aliana-Nasharuddin N.; Asikin-Mijan N.; Abdulkareem-Alsultan G.; Saiman MI.; Alharthi FA.; Alghamdi AA.; Production of green diesel from catalytic deoxygenation of chicken fat oil over a series binary metal oxide-supported MWCNTs. RSC Adv., 2019, 10, 626-42. https://doi.org/10.1039/c9ra08409f.

12. Abdulkareem-Alsultan G.; Asikin-Mijan N.; Taufiq-Yap YH.; Science C.; AbdulkareemAlsultan G.; Asikin-Mijan N.; Effective catalytic deoxygenation of waste cooking oil over nanorods activated carbon supported $\mathrm{CaO}$. Key Eng. Mater., 2016, 707, 175-81. https://doi. org/10.4028/www.scientific.net/KEM.707.175.

13. Abdulkareem-Alsultan G.; Asikin-Mijan N.; Mansir N.; Lee H V.; Zainal Z.; Islam A.; PyroIytic de-oxygenation of waste cooking oil for green diesel production over $\mathrm{Ag}_{2} \mathrm{O}_{3}-\mathrm{La}_{2} \mathrm{O}_{3} /$ AC nano-catalyst. J Anal Appl Pyrolysis., 2018, 137, 171-84. https://doi.org/10.1016/j. jaap.2018.11.023.

14. Abdulkreem-Alsultan G.; Islam A.; Janaun J.; Mastuli MSS.; Taufiq-Yap Y-H.; G. A-A.; Synthesis of structured carbon nanorods for efficient hydrogen storage. Mater Lett., 2016, 179, 57-60. https://doi.org/10.1016/j. matlet.2016.05.030.

15. Abdulkareem-Alsultan G.; Asikin-Mijan N.; Mustafa-Alsultan G.; Lee H V.; Wilson K, Taufiq-Yap YH. Efficient deoxygenation of waste cooking oil over $\mathrm{Co}_{3} \mathrm{O}_{4}$ - $\mathrm{La}_{2} \mathrm{O}_{3}$-doped activated carbon for the production of diesellike fuel. RSC Adv., 2020, 10, 4996-5009. https://doi.org/10.1039/c9ra09516k.

16. Shamil Albazzaz A. Carbon Monoxide Hydrogenation on Activated Carbon Supported Co-Ni Bimetallic Catalysts Via Fischer-Tropsch Reaction to Produce Gasoline. J Energy, Environ Chem Eng., 2018, 3, 40. https://doi. org/10.11648/j.jeece. 20180303.11. 
17. Forum MS. Synthesis and Characterization of Silica- Alumina Supported $\mathrm{Ca}$ and Ni Catalyst for Deoxygenation of Vegetable oil into Diesel 2016. https://doi.org/10.4028/www.scientific. net/MSF.840.353.

18. Lim ST.; Sethupathi S.; Alsultan AG.; Leong LK.; Taufiq-Yap YH. Hydrogen Gas Production Using Aluminum Waste Cans Powder Produced by Disintegration Method. Key Eng Mater., 2020, 853, 228-34. https://doi.org/10.4028/ www.scientific.net/KEM.853.228.

19. Abdulkareem-Alsultan G.; Asikin-Mijan N.; Lee H.V. T-YY.; Abdulkareem-Alsultan G.; AsikinMijan N.; Lee H V.; Taufiq-Yap YH. Biofuels: Past, Present, Future. In: Gupta A.; De A.; Aggarwal S.; Kushari A. RA, editor. Innov. Sustain. Energy Clean. Environ. Green Energy Technol., Springer Singapore., 2020, 489-504. https://doi.org/10.1007/978-981-13-9012-8.

20. Asikin N.; Lee HVHV.; Alsultan GA.; Yap T.; Mijan NA, Lee HVHV.; Synthesis and characterization of silica-alumina supported $\mathrm{Ca}$ and $\mathrm{Ni}$ catalyst for deoxygenation of vegetable oil into diesel. Mater Sci Forum., 2016, 840, 353-8. https://doi.org/10.4028/ www.scientific.net/MSF.840.353.

21. Ibrahim SF.; Asikin-Mijan N.; Ibrahim ML.; Abdulkareem-alsultan G.; Izham SM.; TaufiqYap YH. Sulfonated functionalization of carbon derived corncob residue via hydrothermal synthesis route for esterification of palm fatty acid distillate. Energy Convers Manag., 2020, 210, 112698. https://doi.org/10.1016/j. enconman.2020.112698.

22. Asikin-Mijan N.; Rosman NA.; AbdulKareemAlsultan G.; Mastuli MS.; Lee H V.; NabihahFauzi N, et al. Production of renewable diesel from Jatropha curcas oil via pyrolyticdeoxygenation over various multi-wall carbon nanotube-based catalysts. Process Saf Environ Prot., 2020, 142, 336-49. https://doi. org/10.1016/j.psep.2020.06.034.

23. Khan III.; Saeed K.; Khan III. Nanoparticles: Properties, applications and toxicities. Arab J Chem., 2019, 12, 908-31. https://doi. org/10.1016/j.arabjc.2017.05.011.

24. Asikin-Mijan N.; Lee HV V.; AbdulkareemAlsultan G.; Afandi A.; Taufiq-Yap YHH. Production of green diesel via cleaner catalytic deoxygenation of Jatropha curcas oil. J Clean Prod., 2016, 167, 1-12. https:// doi.org/10.1016/j.jclepro.2016.10.023.

25. Mansir N.; Teo SH.; Rashid U.; Saiman MI.; Tan YP.; Alsultan GA.; Modified waste egg shell derived bifunctional catalyst for biodiesel production from high FFA waste cooking oil. A review. Renew Sustain Energy Rev., 2017. https://doi.org/10.1016/j.rser.2017, 10, 098.

26. Abdulkareem-Alsultan G.; Asikin-mijan N.; Lee H V.; Albazzaz AS.; Taufiq-Yap YH. Deoxygenation of waste cooking to renewable diesel over walnut shell- derived nanorode activated carbon supported $\mathrm{CaO}-\mathrm{La}_{2} \mathrm{O}_{3}$ catalyst. Energy Convers Manag., 2017, 151, 311-23. https://doi.org/http://dx.doi. org/10.1016/j.enconman.2017.09.001.

27. Abdulkareem-Alsultan G.; Asikin-Mijan N.; Lee HV V.; Taufiq-Yap YH. A new route for the synthesis of La-Ca oxide supported on nano activated carbon via vacuum impregnation method for one pot esterificationtransesterification reaction., 2016, 304. https://doi.org/10.1016/j.cej.2016.05.116.

28. Xia Y.; Xiong Y.; Lim B.; Skrabalak SE. Shapecontrolled synthesis of metal nanocrystals: Simple chemistry meets complex physics? Angew Chemie-Int Ed., 2009, 48, 60-103. https://doi.org/10.1002/anie.200802248.

29. Asikin-Mijan N.; Lee HV V.; Juan JCC.; Noorsaadah a. RR, Abdulkareem-Alsultan G, Arumugam M, et al. Waste Clamshell-Derived $\mathrm{CaO}$ Supported $\mathrm{Co}$ and $\mathrm{W}$ catalysts for Renewable Fuels Production Via CrackingDeoxygenation of Triolein. J Anal Appl Pyrolysis., 2016. https://doi.org/10.1016/j. jaap.2016.04.015.

30. Alsultan A.; Mijan A.; Taufiq-Yap YH.; Asikinmijan N.; Yun Hin TY. Preparation of Activated Carbon from Walnut Shell Doped La and Ca Catalyst for Biodiesel Production from Waste Cooking Oil. Mater Sci Forum., 2016, 840, 348-52. https://doi.org/10.4028/www. scientific.net/MSF.840.348.

31. Dreaden EC.; Austin LA.; MacKey MA.; ElSayed MA. Size matters: Gold nanoparticles in targeted cancer drug delivery. Ther Deliv., 2012, 3, 457-78. https://doi.org/10.4155/tde.12.21. 
32. Asikin-Mijan N.; Lee HV V.; Taufiq-Yap YH.; Abdulkrem-Alsultan G.; Mastuli MSS.; Ong HC. Optimization study of $\mathrm{SiO}_{2}-\mathrm{Al}_{2} \mathrm{O}_{3}$ supported bifunctional acid-base $\mathrm{NiO}-\mathrm{CaO}$ for renewable fuel production using response surface methodology. Energy Convers Manag., 2016. https://doi.org/10.1016/j. enconman.2016.09.041.

33. Majidi S.; Sehrig FZ.; Farkhani SM.; Goloujeh MS.; Akbarzadeh A. Current methods for synthesis of magnetic nanoparticles. Artif Cells, Nanomedicine Biotechnol., 2016, 44, 722-34. https://doi.org/10.3109/21691401.2 014.982802

34. Xin Y.; Zhang N.; Lv Y.; Wang J.; Li Q.; Zhang Z. From nanoparticles to single atoms for $\mathrm{Pt} / \mathrm{CeO}_{2}$ : Synthetic strategies, characterizations and applications. J Rare Earths., 2020, 38, 850-62. https://doi. org/10.1016/j.jre.2020.03.007.

35. Hou S.; Wang X.; Huang C.; Xie C.; Yu S. Highly Selective Hydrogenation of $\alpha$-Pinene Catalyzed by Ru Nanoparticles in Aqueous Micellar Microreactors. Catal Letters., 2016, 146, 580-6. https://doi.org/10.1007/s10562015-1685-2.

36. Abdulkareem-Alsultan G.; Asikin-Mijan N.; Lee H V.; Rashid U.; Islam A.; Taufiq-Yap YH. A Review on Thermal Conversion of Plant Oil (Edible and Inedible) into Green Fuel Using
Carbon-Based Nanocatalyst. Catalysts., 2019, 9, 350. https://doi.org/10.3390/ catal9040350.

37. Asikin-Mijan N.; Ooi JMM.; AbdulKareemAlsultan G.; Lee HV V.; Mastuli MSS.; Mansir $\mathrm{N}$; Free-H2 deoxygenation of Jatropha curcas oil into cleaner diesel-grade biofuel over coconut residue-derived activated carbon catalyst. J Clean Prod., 2020, 249, 119381. https://doi.org/10.1016/j.jclepro. 2019.119381.

38. Takai ZI.; Mustafa MK.; Asman S.; Sekak KA. Preparation and characterization of magnetite $\left(\mathrm{Fe}_{3} \mathrm{O}_{4}\right)$ nanoparticles by sol-gel method. Int J Nanoelectron Mater., 2019, 12, 37-46.

39. Yamashita K.; Okada S.; Sawada H. Preparation of fluoroalkyl end-capped vinyltrimethoxysilane oligomeric silica/ magnetite composites- Application to separation of oil and water. Colloids Surfaces A Physicochem Eng Asp., 2019, 581, 123668. https://doi.org/10.1016/j. colsurfa.2019.123668.

40. Abdulkareem-Alsultan G.; Asikin-Mijan N.; Mustafa-Alsultan G.; Lee H V.; Wilson K.; Taufiq-Yap YH. Efficient deoxygenation of waste cooking oil over $\mathrm{Co}_{3} \mathrm{O}_{4}-\mathrm{La}_{2} \mathrm{O}_{3}$-doped activated carbon for the production of diesellike fuel. RSC Adv., 2020, 6, 17423-9. https:// doi.org/10.1039/c9ra09516k. 